\title{
The Effect of Long-Term Hypogonadism on Body Composition and Morphometry of Aged Male Wistar Rats
}

\author{
Veronika BORBÉLYOVÁ ${ }^{1}$, Veronika ŠARAYOVÁ ${ }^{1,2}$, Emese RENCZÉS ${ }^{1}$, Jozef ČONKA ${ }^{1}$, \\ Jakub JANKO ${ }^{1}$, Katarína Š́EBEKOVÁ ${ }^{1}$, Kornélia ŠTEFÍKOVÁ ${ }^{3}$, Daniela OSTATNÍKOVÁ, \\ Peter CELEC ${ }^{1,5,6}$
}

${ }^{1}$ Institute of Molecular Biomedicine, Faculty of Medicine, Comenius University, Bratislava, Slovak Republic, ${ }^{2}$ Institute of Biology, Faculty of Medicine, Slovak Medical University, Bratislava, Slovak Republic, ${ }^{3}$ Department of Clinical and Experimental Pharmacology, Faculty of Medicine, Slovak Medical University, Bratislava, Slovak Republic, ${ }^{4}$ Academic Research Centre for Autism, Institute of Physiology, Faculty of Medicine in Bratislava, Comenius University, Bratislava, Slovak Republic, ${ }^{5}$ Institute of Pathophysiology, Faculty of Medicine, Comenius University, Bratislava, Slovak Republic, ${ }^{6}$ Department of Molecular Biology, Faculty of Natural Sciences, Comenius University, Bratislava, Slovak Republic

Received April 15, 2021

Accepted November 11, 2021

\section{Summary}

Clinical studies show that hypogonadism in the aging male is associated with obesity and osteoporosis. Experimental studies are mostly conducted on relatively young adult animals and the induced hypogonadism lasts for a relatively short time. The present study aimed to describe the effect of long-term hypogonadism beginning in puberty on body composition, morphometry, and bone mineral density in aged male rats. Morphometric measurements and dual-energy $\mathrm{X}$-ray absorptiometry were conducted at the age of 30 months on control and gonadectomized males. Long-term hypogonadism did not affect body weight, but led to a higher fat mass (by $26 \%$ ), lower lean mass (by $44 \%$ ), shorter body length (by $9 \%$ ), and anogenital distance (by $26 \%$ ), as well as to lower tail circumference (by $15 \%$ ) in comparison to control males. Lower bone mineral density (by $13 \%$ ) and bone mineral content (by $15 \%$ ) were observed in gonadectomized males. Results showing sarcopenic obesity and osteoporosis in this model of long-term hypogonadism might mimic the situation in aging males better than the widely used short-term hypogonadism induced in young animals. The morphometric analysis could potentially be a useful tool to study normal weight obesity without the need for specific equipment.

\section{Key words}

Body Proportion • Bone Metabolism • Castration • Muscle Mass • Old age

\section{Corresponding author}

V. Borbélyová, Institute of Molecular Biomedicine, Faculty of Medicine, Comenius University, Sasinkova 4, 81108 Bratislava, Slovak Republic. E-mail: borbelyova.veronika88@gmail.com

\section{Introduction}

In men, aging is associated with a decline of sex steroid hormones, such as testosterone (Harman et al. 2001). The prevalence of older men suffering from hypogonadism (Taylor et al. 2015) and obesity has an increasing tendency worldwide (Villareal et al. 2005, Wannamethee et al. 2015). There is an inverse relationship between low testosterone concentration and obesity (Diaz-Arjonilla et al. 2009) measured as high body mass index (Zumoff et al. 1990, Pasquali et al. 1991, Gapstur et al. 2002, Svartberg et al. 2004, Kaplan et al. 2006). In the elderly, low concentrations of androgens are associated with a higher fat mass, lower lean body mass, and muscle strength (Katznelson et al. 1996, Torremade-Barreda et al. 2013, Moran et al. 2015, 
Dias et al. 2016), even in those with stable normal body weight - the so-called sarcopenic obesity (Lim et al. 2010, Choi 2016). Furthermore, long-term androgen deficiency is associated with the loss of bone mineral density (Katznelson et al. 1996, Torremade-Barreda et al. 2013, Moran et al. 2015, Dias et al. 2016), leading to osteoporosis (Mellstrom et al. 2006, Meier et al. 2008).

In humans, the assessment of obesity includes anthropometric measures such as body mass index (BMI) and waist circumference, the latter being more appropriate for the measurement of adiposity than BMI mainly in older patients (Ruff 2000, Ledikwe et al. 2003). In addition, morphometric measurements, especially abdominal circumference, are also commonly used in animal studies as an inexpensive, quick, and easy method for the assessment of obesity (Novelli et al. 2007, Gerbaix et al. 2010, Malafaia et al. 2013, Mamikutty et al. 2014). However, in humans, for accurate measurement of body composition, especially in sarcopenic obesity, more sophisticated methods allowing simultaneous measurement of fat and lean components are used, such as dual-energy X-ray absorptiometry (DEXA) (Baumgartner 2000, Lee et al. 2008). Whether simple morphometric measurements can be used for reliable evaluation of obesity in really aged laboratory animals, have not been elucidated yet.

The commonly used animal model of androgen deficiency is the removal of the primary endogenous androgen source - the testes - via gonadectomy. Gonadectomized animals usually show unaltered (Vanderschueren et al. 2000, Jiao et al. 2009, DeGuire et al. 2015, Zügel et al. 2016) or lower (Wade et al. 1984, Potikanond et al. 2016) fat mass, lower lean mass (Vanderschueren et al. 2000, Venken et al. 2005, Jiao et al. 2009, DeGuire et al. 2015), lower bone mineral content and density leading to osteoporosis (Vanderschueren et al. 2000, Moreau et al. 2001, Attardi et al. 2011, Potikanond et al. 2016, Jayusman et al. 2018, Jayusman et al. 2018, Li et al. 2018). However, the vast majority of the aforementioned studies are focused on the effect of short-term hypogonadism (weeks to months) on the body composition and bone metabolism of adult animals. Data on body composition following long-term androgen depletion are scarce and usually do not focus on the morphometric measurements in aged animals (Borbélyová et al. 2017). Whether hypogonadism lasting for more than 2 years alters body composition and bone metabolism in aged rats is unknown. Similarly, the causal relationship between long-term androgen depletion and morphometric variables in aged rats has not been investigated yet.

Therefore, the main goal of the present study was to investigate the effect of gonadectomy-induced long-term androgen deficiency on morphometric parameters, bone mineral content and density, and body composition of 30-month-old male Wistar rats. We have hypothesized that gonadectomized males will display higher body weight and fat mass, and lower lean mass compared to control males.

\section{Materials and Methods}

\section{Ethical statement}

All experimental procedures were approved by the Ethical Committee of the Institute of Molecular Biomedicine, Comenius University, Bratislava, and have been conducted in accordance with the EU Directive 2010/63/EU and Slovak legislation.

\section{Animals and housing conditions}

Wistar albino male rats $(n=12)$ at the age of 1 month were purchased from Anlab (Prague, Czech Republic). Animals were group-housed (3-4 per cage) in polycarbonate cages $(50 \times 36 \times 19 \mathrm{~cm})$ and kept under standard laboratory conditions (temperature $22 \pm 2{ }^{\circ} \mathrm{C}$, humidity $55 \pm 10 \%$ and 12:12 light-dark cycle). Access to food (standard diet for rats KKZ-P/M, Dobrá Voda) and water was ad libitum.

\section{Surgery}

Rats were randomly divided into two groups: control $(n=7)$ and gonadectomized males $(n=5)$. One rat from gonadectomized group did not recover after surgery and one died during the experiment. The post-hoc power analysis with this number of animals showed at $\mathrm{p}=0.05$ power $99.9 \%$ for testosterone concentration, and power $>80 \%$ for the rest of the measurements listed below. Gonadectomy was performed on postnatal day 47 , under anesthesia with intraperitoneal administration of ketamine (100 mg/kg, Narkamon inj, Bioveta, Czech Republic) and xylazine (10 mg/kg, Xylariem inj, Riemser, Germany). Bilateral gonadectomy was performed through a small incision at the posterior tip of the scrotum, after ligation of vas deferens and spermatic blood vessels with a silk suture. Sham castration was performed on control males. The procedure included displacement of the gonads from the scrotum, followed by their immediate replacement. To minimize postoperative pain, buprenorphine 
$(0.05 \mathrm{mg} / \mathrm{kg})$ in a volume of $0.1 \mathrm{ml} / \mathrm{kg}$ body weight was administered subcutaneously at the end of the surgery, immediately after the incision was closed and also before the animals regained consciousness. Following surgery, rats were group-housed with their previous cage mates until the age of 30 months.

\section{Morphometric measurements in rats}

At the age of 30 months, under anesthesia (intraperitoneal administration of ketamine $(100 \mathrm{mg} / \mathrm{kg})$ and xylazine $(10 \mathrm{mg} / \mathrm{kg})$, rats underwent morphometric measurements according to the protocol of (Aguh et al. 2013). Tail length, tail circumference, and head length were measured in the prone position of the rat on the laboratory desk. Body length from nose to anus, anogenital distance, and waist circumference were measured in the supine position of the rat on the laboratory desk. Different instruments (caliper, measuring tape, ruler, scale, and thread) were used to measure these variables.

Tail length (TL, cm) means the distance between the tail base and its tip. Tail circumference (TC, $\mathrm{cm})$ was measured as the perimeter of the tail at its base. Head length (HL, cm) was considered as the distance between the nose tip and back of the ear pinna. Nose-to-anus body length (NABL, cm) was measured as the distance from the nose to the anus. Waist circumference (WC, $\mathrm{cm}$ ) was measured at the level of the belly button (Schroeder et al. 2008) (Fig. 1A). Anogenital distance (AGD, cm) reflects the distance from the base of the genital papilla to the rostral end of the anal opening (Aguh et al. 2013) (Fig. 1B). Body mass index (BMI) was calculated as: body weight/body length ${ }^{2}\left(\mathrm{~g} / \mathrm{cm}^{2}\right)$.

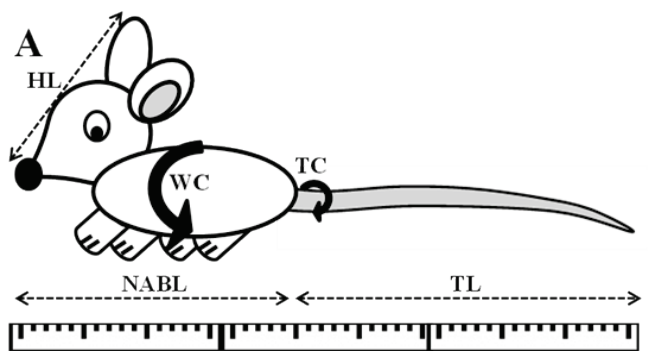

\section{Dual-energy X-ray absorptiometry in rats}

To evaluate body composition and bone mass, DEXA was used (Grier et al. 1996). This non-invasive technique is based on the attenuation of x-ray beams by tissues and enables its application in small animals. The whole-animal DEXA measurement was performed using the LUNAR Prodigy Advance device (GE Medical Systems, Madison, WI, USA) and data were analyzed using Encore TM 2011 software (version 13.60). Calibration was done before the measurements according to the instructions of the manufacturer. The scanner performance was controlled using the quality assurance protocol of the laboratory. Rats were placed on a polystyrene mat on the top of the scanner table. Under anesthesia, rats were straightened and laid flat on the ventral face along the long axis of the scanning area with a complete abduction of the four limbs. Only upper limbs were fixed with textile bands to the polystyrene mat. The tail was bent laterally to reduce scan time. After manually positioning the rat and laser beam for marking the start of a scan, the measurements were performed in a fully automated manner.

Based on the attenuation of the two energy levels, the system provides quantitative data on the bone mineral content (BMC; g), the fat tissue content $(\mathrm{g})$, and the lean tissue content $(\mathrm{g})$. By delineating the projection area of the bones, the software additionally provides the areal bone mineral density (BMD; $\mathrm{g} / \mathrm{cm}^{2}$ ) (Lochmüller et al. 2001). All measurements and analyzes of DEXA images were performed by the same investigator.

\section{Locomotor activity in rats}

To assess the locomotor activity of aged rats, the open field test was used. The apparatus consisted of a square arena $(100 \mathrm{~cm} \times 100 \mathrm{~cm})$ virtually divided into the central zone $(40 \mathrm{~cm} \times 40 \mathrm{~cm})$ and border zone. Rats were placed into the center of the open field arena and were allowed to freely explore it for $5 \mathrm{~min}$. Total distance moved was observed to evaluate the locomotor activity of rats. The open field arena was cleaned with a damp cloth containing Incidur spray (Ecolab, Dusseldorf, Germany) between tested animals.

\section{Blood collection and hormone assay}

To assess plasma testosterone concentrations, blood samples were collected from the tail vein 
of 30-month-old rats. Blood samples were centrifuged at $2000 \times \mathrm{g}$ for $5 \mathrm{~min}$. The measurement of plasma testosterone concentration was conducted using the commercially available ELISA kit (DRG Diagnostic, Marburg, Germany) according to the instructions of the manufacturer. The analytical sensitivity was $0.083 \mathrm{ng} / \mathrm{ml}$. The average intra-assay coefficient of variation for the testosterone assay was below $5 \%$ and the inter-assay coefficient of variation was below $10 \%$.

\section{Statistical analysis}

Statistical analysis was performed using IBM SPSS Statistics v. 20.0 (IBM, Armonk, NY, USA) and GraphPad Prism version 6 (GraphPad Software, Inc., CA, USA). The normality of data distribution was verified using the D'Agostino test. For comparison of control and gonadectomized rats, an independent-samples Student's $t$-test (two-sided) was used. $\mathrm{p}<0.05$ were considered statistically significant. Data are presented as mean plus standard deviation (SD).

\section{Results}

Long-term androgen deficiency influences the body composition and morphometric parameters of the aged rats

Androgen deficiency was confirmed by measurement of plasma testosterone concentration in 30-month-old rats. Aged gonadectomized males had significantly lower plasma testosterone concentration compared to control males $(2.17 \pm 0.46$ vs. $5.11 \pm 1.43 \mathrm{nmol} / 1, \mathrm{p}<0.01)$.

At the age of 30 months, the body weight of gonadectomized rats did not differ from that of the control males $(562 \pm 28$ g vs. $497 \pm 19$ g, p=0.11, Fig. $2 A)$. There were significant differences in body composition between the groups. Higher amount of fat mass (291.6 \pm 30.0 g vs. $217.0 \pm 49.6$ g, p<0.05, Fig. 2B) and conversely, a lower amount of lean mass was detected in gonadectomized males $(189.9 \pm 26.0 \mathrm{~g}$ vs. $338.4 \pm 35.9 \mathrm{~g}$, $\mathrm{p}<0.001$, Fig. 2C) compared to the control group. Additionally, gonadectomy led to higher fat to tissue ratio (60.6 \pm 3.7 vs. $38.8 \pm 5.1 \%, \mathrm{p}<0.001$, Fig. $2 \mathrm{D})$.
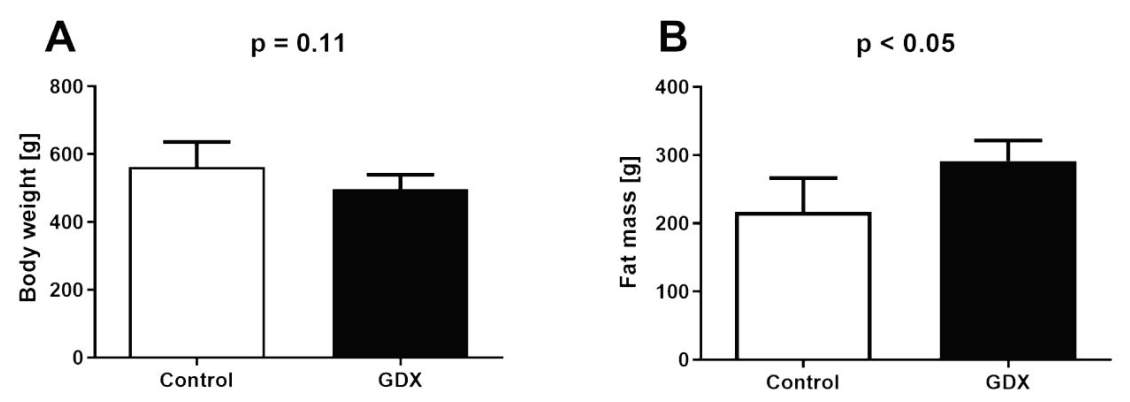

Fig. 2. Body weight and body composition in 30-month-old Wistar rats. Body weight (A) did not differ between gonadectomized and control males. More fat mass (B) and less lean mass (C) was detected in gonadectomized males compared to controls. Following these results, fat to tissue ratio (D) was higher in gonadectomized males. Values are expressed as means $+\mathrm{SD}$.
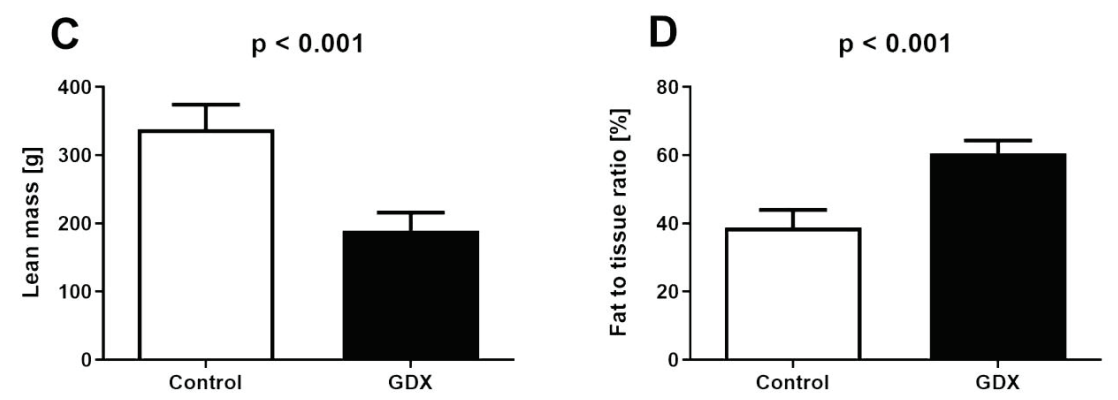

Gonadectomy resulted in a significantly shorter anogenital distance $(3.9 \pm 0.6$ vs. $5.4 \pm 0.4 \mathrm{~cm}, \mathrm{p}<0.001$, Fig. $3 \mathrm{~A})$ and tail circumference $(2.7 \pm 0.1$ vs. $3.2 \pm 0.2 \mathrm{~cm}$, $\mathrm{p}<0.001$, Fig. 3B) compared to control males.

In addition, shorter nose-anus body length $(24.1 \pm 0.7$ vs. $26.4 \pm 1.2 \mathrm{~cm}, \mathrm{p}<0.01)$ was observed in gonadectomized males compared to controls (Fig. 4). Tail length $(19.8 \pm 0.4 \mathrm{~cm}$ vs. $19.1 \pm 0.3 \mathrm{~cm}, \mathrm{p}=0.30)$ was not affected by long-term androgen deficiency. The values of waist circumference were similar for both groups (20.5 $\pm 0.4 \mathrm{~cm}$ vs. $20.0 \pm 0.4 \mathrm{~cm}, \mathrm{p}=0.49$ ). The BMI did not significantly differ between the groups $\left(8.3 \pm 0.3 \mathrm{~g} / \mathrm{cm}^{2}\right.$ vs. $7.5 \pm 0.5 \mathrm{~g} / \mathrm{cm}^{2}, \mathrm{p}=0.26$ ). 
A

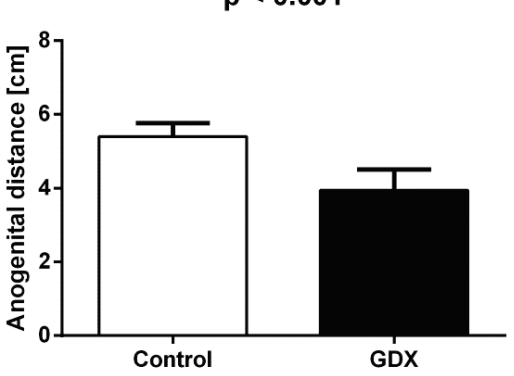

B

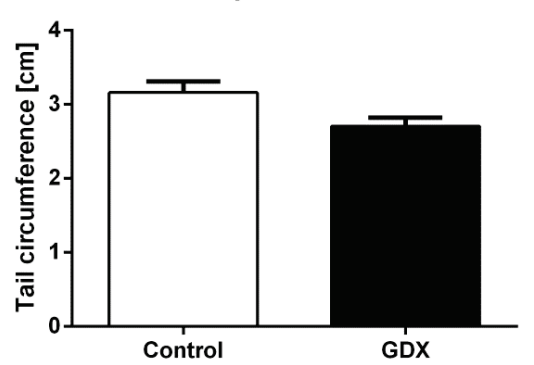

Fig. 3. Anogenital distance and tail circumference of 30-month-old Wistar rats. Aged gonadectomized males had a shorter anogenital distance (A) and lower tail circumference (B) than control males. Values are expressed as means + SD.
Long-term androgen deficiency affects the bone mineral density and content in aged rats

Densitometric measurements revealed lower bone mineral density $\left(0.202 \pm 0.01\right.$ vs. $0.232 \pm 0.00 \mathrm{~g} / \mathrm{cm}^{2}$, $\mathrm{p}<0.001$, Fig. 5A) as well as bone mineral content $(17.68 \pm 1.32$ vs. $20.70 \pm 1.45 \mathrm{~g}, \quad \mathrm{p}<0.01$, Fig. $5 \mathrm{~B})$ in gonadectomized males compared to controls. Bone area values did not differ significantly between gonadectomized $\left(86.6 \pm 3.0 \mathrm{~cm}^{2}\right)$ and control rats $\left(88.2 \pm 2.8 \mathrm{~cm}^{2}\right)$.

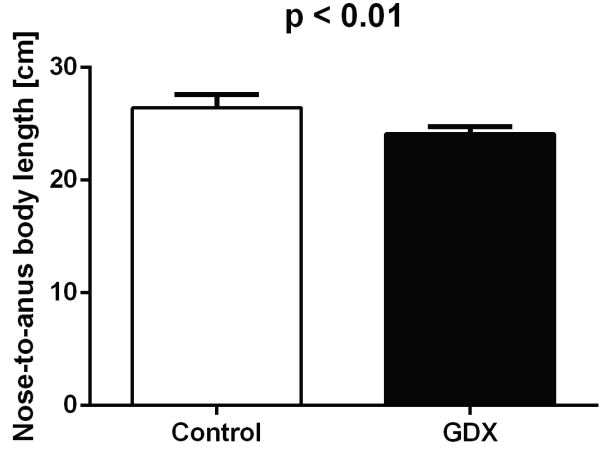

Fig. 4. Nose-to-anus body length in 30-month-old Wistar rats. Gonadectomized males had shorter nose-anus body length than control males. Values are expressed as means $+\mathrm{SD}$.
A

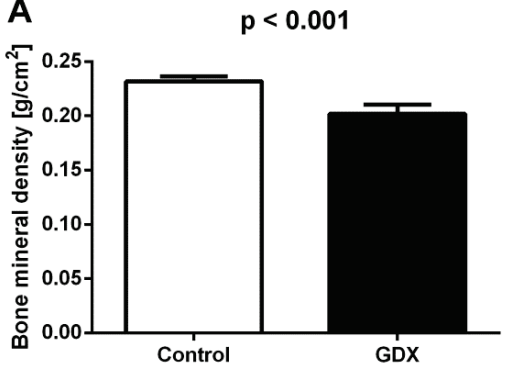

B

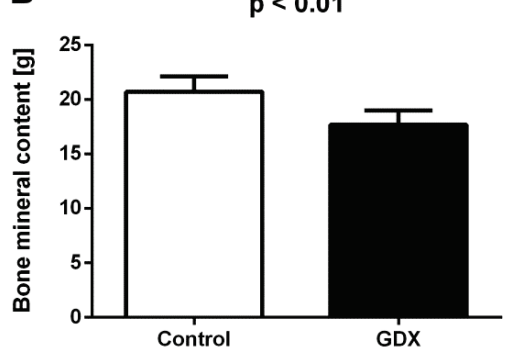

Fig. 5. Bone mineral density and content in 30-month-old Wistar rats. Long-term androgen deficiency resulted in a reduction of both, bone mineral density (A) and content (B) in aged rats. Values are expressed as means + SD.
To assess whether lower muscle mass is caused by lower locomotor activity in the gonadectomized group, rats were tested in the open field test (Fig. 6). No significant differences were observed in locomotor activity of rats measured as total distance moved in the open field test $(\mathrm{p}=0.54)$, suggesting that lower bone mass in GDX rats is probably the result of long-term androgen deficiency.

\section{Discussion}

The link between hypogonadism and alterations in body composition and bone metabolism has been proved by both, clinical (Katznelson et al. 1996, Torremade-Barreda et al. 2013, Moran et al. 2015, Dias et al. 2016) and experimental studies (Wade et al. 1984, Vanderschueren et al. 2000, Moreau et al. 2001, Venken et al. 2005, Jiao et al. 2009, Attardi et al. 2011, DeGuire et al. 2015, Potikanond et al. 2016, Jayusman et al. 2018, Jayusman et al. 2018, Li et al. 2018).

$$
p=0.54
$$

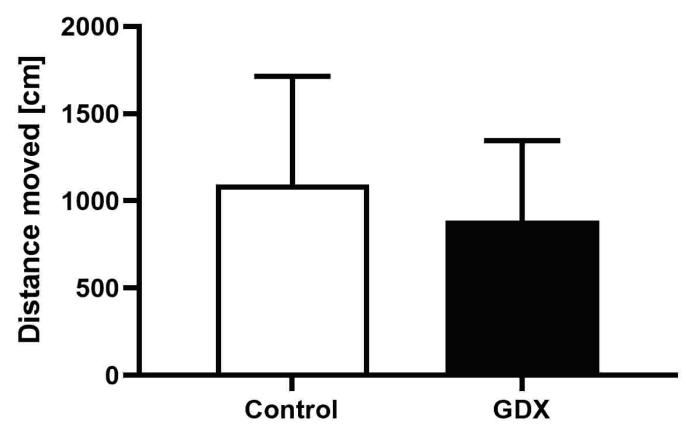

Fig. 6. Locomotor activity of 30-month-old Wistar rats. Control and GDX rats displayed similar locomotor activity in the open field test. Values are expressed as means + SD. 
However, the vast majority of experimental studies have focused on the effect of relatively short-term hypogonadism lasting either 1-2 months (Kakolewski et al. 1968, Vanderschueren et al. 1992, Borst et al. 2006, Christoffersen et al. 2006, Jiao et al. 2009, Chin et al. 2016, Starcevic et al. 2017, Jayusman et al. 2018, Jayusman et al. 2018, Doulamis et al. 2019) or 3-4 months in adult (Wade et al. 1984, Moreau et al. 2001, Attardi et al. 2011, Harada et al. 2016, Potikanond et al. 2016, Zügel et al. 2016, Saki et al. 2018) or aged animals (Vanderschueren et al. 1992, Vanderschueren et al. 2000, Venken et al. 2005, DeGuire et al. 2015) on body composition and bone metabolism. Although the effect of long-term androgen deficiency is clinically more relevant for investigation of the effect of hypogonadism on body composition, morphometry, and bone metabolism in humans, experimental studies evaluating the impact of such long-term androgen depletion are lacking. Therefore, the present study aimed to describe the effect of long-term hypogonadism beginning in puberty on body composition, morphometry, and bone mineral density in aged, 30-month-old male rats. In the current study, long-term androgen deficiency led to lower lean mass and higher fat mass, with no changes in body weight in aged rats mimicking sarcopenic obesity in humans. These changes were not caused by altered locomotor activity. Aged gonadectomized rats had lower bone mineral density and bone mineral content compared to controls that imitate osteoporosis in the elderly. Moreover, morphometric analysis in aged rats revealed a shortening of body length, anogenital distance, and lowering of tail circumference following androgen deficiency lasting more than two years compared to that of control males.

In the present study, long-term androgen depletion starting at puberty did not affect the body weight of 30-month-old gonadectomized animals. The only study, with a similar duration of androgen deprivation (18-month-long), however, not focused on body composition, morphometry, and bone metabolism is our previous study, where we also did not find differences in body weight of aged rats following longterm androgen deficiency when compared to controls (Borbélyová et al. 2017). Previous studies have shown that short-term (lasting 1-2 months) androgen deficiency in adulthood results in either lower (Kakolewski et al. 1968, Borst et al. 2006, Jiao et al. 2009) or no changes in body weight (Christoffersen et al. 2006, Chin et al. 2016, Starcevic et al. 2017, Doulamis et al. 2019) of rats compared to control males. The majority of experimental studies have reported lower body weight of adult mice (Harada et al. 2016) and rats (Moreau et al. 2001, Attardi et al. 2011, Potikanond et al. 2016, Saki et al. 2018) following 3-4-month-long androgen depletion. Contradictory findings reporting no changes in body weight following similar duration of androgen deficiency in adult hamsters (Wade et al. 1984) and rats (Zügel et al. 2016, Li et al. 2018) have been also shown. On the contrary, it has been demonstrated that androgen deficiency (3-4-month-long) induced in aged guinea pigs (DeGuire et al. 2015) and aged rats results in lower (Vanderschueren et al. 1992, Venken et al. 2005) or similar body weight (Vanderschueren et al. 2000) compared to control males. According to these results, it seems that androgen depletion induced either in adulthood or during aging could have body weightlowering effects as well as could result in no changes in body weight. In the current study, however, we did not focus on the dynamics of the effects of long-term gonadectomy on body composition and morphometry, thus, the changes in body weight could be observable earlier during the aging of animals.

The main difference between the current and previous experimental studies dealing with the effect of androgen depletion on body composition and bone metabolism besides the species used (mice, guinea pigs, hamsters vs. rats) and age of animals at androgen deficiency initiation is mainly the duration of hypogonadism. The present study demonstrates that longterm androgen deprivation leads to lower muscle mass that is more pronounced than the increase of fat mass in gonadectomized male rats in comparison to controls. Thus, it seems, that long-term androgen depletion in aged animals affects more the muscle mass compared to fat mass, that is supported by a study by DeGuire et al. (2015) (DeGuire et al. 2015) reporting reduced lean mass already 2 weeks following gonadectomy (and also during a 4-month-long observing period) in aged, 18-month-old guinea pigs. On the contrary, the study of (Brown et al. 2001) showed no changes in muscle mass 2 weeks after gonadectomy in adult (6-month-old) rats. In addition, no changes in lean mass even following 3-month-long androgen depletion have been shown in adult rats (Zügel et al. 2016). Based on these results, younger adult rats may be more resistant to gonadectomy-induced muscle loss than aged animals.

It has been shown that short-term androgen deficiency (lasting 2-4 months) in adult rats led to lower 
lean mass (Moreau et al. 2001, Jiao et al. 2009) without any change in fat mass compared to control males. Similarly, short-term androgen depletion (lasting 3-4 months) in either aged guinea pigs (DeGuire et al. 2015) or aged rats (Vanderschueren et al. 2000, Venken et al. 2005) resulted in lower lean mass with unchanged fat mass compared to control animals. These results together with the results of the present study suggest that compared to muscles, the manifestation of changes in the amount of fat mass requires a longer time. Thus, in the current experiment, androgen deficiency lasting more than two years resulted in a serious loss of muscle mass and slower fat mass gain during the aging of rats, and in turn, the body weight of gonadectomized rats remained stable mimicking sarcopenic obesity of humans.

Numerous experimental studies have shown a decrease in bone mass (measured as bone mineral density and bone mineral content) in adult rats following a short-term, either 1-2-month-long androgen deficiency (Jayusman et al. 2018, Jayusman et al. 2018) or 3-4-month-long androgen depletion (Moreau et al. 2001, Attardi et al. 2011, Potikanond et al. 2016, Li et al. 2018, Saki et al. 2018). Similarly, aged rats (Vanderschueren et al. 1992, Vanderschueren et al. 2000, Venken et al. 2005, Potikanond et al. 2016, Saki et al. 2018) and guinea pigs (DeGuire et al. 2015) following a short-term, 3-4-month-long androgen depletion, display lower bone mineral content and lower bone mineral density in comparison to control animals. Therefore, it could be argued that androgen depletion leads to a reduction of bone mineral density and bone mineral content independently of the age at gonadectomy induction. Although, (Vanderschueren et al. 1992) have reported that androgen deficient aged male rats had a lower bone mass following 4 months, but not 1 month after gonadectomy, suggesting that in aged animals bone loss occurs apparently slower than in younger adult animals (Vanderschueren et al. 1992), which may be related to a physiological decrease in bone turnover during aging (Demontiero et al. 2012). Therefore, our findings are in line with the previously published data as we have found lower bone mineral content and bone mineral density in 30-month-old rats following long-term androgen depletion, suggesting the presence of osteoporosis in aged rats.

To the best of our knowledge and in comparison to other studies, the current study is the first one investigating the effect of long-term hypogonadism lasting for more than 2 years on body composition and bone metabolism in 30-month-old Wistar rats. In addition, in the present study, the most widely used model of male osteoporosis, surgical castration by orchiectomy, was used. In comparison to other experimental studies, this study is the first that analyzes the effect of long-term androgen depletion on the whole palette of morphometric measurements in 30-month-old Wistar rats. However, it is also affected by several limitations. All measurements were conducted only once, at the age of 30-months, and we have not analyzed the dynamics of changes in body weight, morphometric parameters, body composition, and bone metabolism during the aging process. A missing group of gonadectomized rats with testosterone supplementation will provide evidence of the key role of testosterone in the shaping of body composition and bone metabolism during the aging of rats. Another limitation of our study is that calcium metabolism, crucial for bone formation, was not analyzed. Testosterone or the lack of it affects calcium via modulating calcium absorption in the gut, but also via affecting reabsorption in the kidney. This should be taken into account in future studies.

\section{Conclusions}

In conclusion, our data show that long-term hypogonadism results in sarcopenic obesity and osteoporosis in aged rats. This model of long-term hypogonadism might be clinically more relevant than currently used experimental models of short-term hypogonadism in young adult animals. Further studies are needed to uncover the chronology of manifestation of observed changes in body morphology and composition, and also bone metabolism together with monitoring of calcium concentrations following gonadectomy throughout aging. If the present findings from morphometric analysis will be reproducible in other models of hypogonadism it could be used as a possible tool for diagnosis of sarcopenic obesity without the need for specific equipment as DEXA.

\section{Conflict of Interest}

There is no conflict of interest.

\section{Acknowledgements}

This research was funded by the Slovak Research and Development Agency [APVV-15-0045] and the Ministry of Education of the Slovak Republic [VEGA $1 / 0635 / 20]$. This article was created by the realization of 
the project "Center of excellence of environmental health", ITMS No. 26240120033, based on the supporting operational Research and development program financed from the European Regional Development Fund.

\section{References}

AGUH BI, YAHAYA A, SAIDU IA, AYEKU PO, AGBA AA: Correlation of body weight and other morphometric measurements in Albino rats (Rattus Norvegicus). Sci J Biol Sci 2: 39-44, 2013. https://doi.org/10.14196/SJBS.V2I3.527

ATTARDI BJ, MARCK BT, MATSUMOTO AM, KODURI S, HILD SA: Long-term effects of dimethandrolone

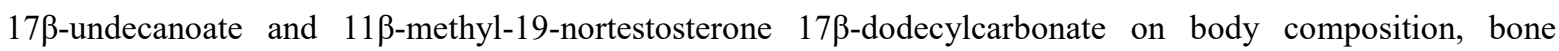
mineral density, serum gonadotropins, and androgenic/anabolic activity in castrated male rats. J Androl 32: 183-192, 2011. https://doi.org/10.2164/jandrol.110.010371

BAUMGARTNER RN: Body composition in healthy aging. Ann N Y Acad Sci 904: 437-448, 2000. https://doi.org/10.1111/j.1749-6632.2000.tb06498.x

BORBÉLYOVÁ V, DOMONKOS E, BÁBÍČKOVÁ J, TÓTHOVÁ L, KAČMÁROVÁ M, ULIČNÁ O, OSTATNÍKOVÁ D, HODOSY J, CELEC P: Does long-term androgen deficiency lead to metabolic syndrome in middle-aged rats? Exp Gerontol, 98: 38-46, 2017. https://doi.org/10.1016/j.exger.2017.08.016

BORST SE, CONOVER CF: Orchiectomized Fischer 344 male rat models body composition in hypogonadal state. Life Sci 79: 411-415, 2006. https://doi.org/10.1016/j.lfs.2006.01.035

BROWN M, FISHER JS, HASSER EM: Gonadectomy and reduced physical activity: effects on skeletal muscle. Arch Phys Med Rehabil 82: 93-97, 2001. https://doi.org/10.1053/apmr.2001.18697

CHIN KY, GENGATHARAN D, MOHD NASRU FS, KHAIRUSSAM RA, ERN SL, AMINUDDIN SA, IMA-NIRWANA S: The effects of annatto tocotrienol on bone biomechanical strength and bone calcium content in an animal model of osteoporosis due to testosterone deficiency. Nutrients 8, 2016. https://doi.org/10.3390/nu8120808

CHOI KM: Sarcopenia and sarcopenic obesity. Korean J Intern Med 31: 1054-1060, 2016. https://doi.org/10.3904/kjim.2016.193

CHRISTOFFERSEN B, RAUN K, SVENDSEN O, FLEDELIUS C, GOLOZOUBOVA V: Evalution of the castrated male Sprague-Dawley rat as a model of the metabolic syndrome and type 2 diabetes. Int J Obes (Lond) 30: 1288-1297, 2006. https://doi.org/10.1038/sj.ijo.0803261

DEGUIRE JR, MAK IL, LAVERY P, AGELLON S, WYKES LJ, WEILER HA: Orchidectomy-induced alterations in volumetric bone density, cortical porosity and strength of femur are attenuated by dietary conjugated linoleic acid in aged guinea pigs. Bone 73: 42-50, 2015. https://doi.org/10.1016/j.bone.2014.12.005

DEMONTIERO O, VIDAL C, DUQUE G: Aging and bone loss: new insights for the clinician. Ther Adv Musculoskelet Dis 4: 61-76, 2012. https://doi.org/10.1177/1759720X11430858

DIAS JP, MELVIN D, SIMONSICK EM, CARLSON O, SHARDELL MD, FERRUCCI L, CHIA CW, BASARIA S, EGAN JM: Effects of aromatase inhibition vs. testosterone in older men with low testosterone: randomized-controlled trial. Andrology 4: 33-40, 2016. https://doi.org/10.1111/andr.12126

DIAZ-ARJONILLA M, SCHWARCZ M, SWERDLOFF RS, WANG C: Obesity, low testosterone levels and erectile dysfunction. Int J Impot Res 21: 89-98, 2009. https://doi.org/10.1038/ijir.2008.42

DOULAMIS IP, TZANI A, KONSTANTOPOULOS P, DASKALOPOULOU A, SPINOS T, BLETSA E, MITSOPOULOU D, SPINOU M, BRINIA ME, PALAIOPANOS K, KOROU LM, PERREA DN, KATSILAMBROS NL: Experimental hypogonadism: insulin resistance, biochemical changes and effect of testosterone substitution. J Basic Clin Physiol Pharmacol 30, 2019. https://doi.org/10.1515/jbcpp-2018-0118

GAPSTUR SM, GANN PH, KOPP P, COLANGELO L, LONGCOPE C, LIU K: Serum androgen concentrations in young men: a longitudinal analysis of associations with age, obesity, and race. The CARDIA male hormone study. Cancer Epidemiol Biomarkers Prev 11: 1041-1047, 2002. 
GERBAIX M, METZ L, RINGOT E, COURTEIX D: Visceral fat mass determination in rodent: validation of dual-energy X-ray absorptiometry and anthropometric techniques in fat and lean rats. Lipids Health Dis 9: 140, 2010. https://doi.org/10.1186/1476-511X-9-140

GRIER SJ, TURNER AS, ALVIS MR: The use of dual-energy x-ray absorptiometry in animals. Invest Radiol 31: 50-62, 1996. https://doi.org/10.1097/00004424-199601000-00008

HARADA N, HANAOKA R, HORIUCHI H, KITAKAZE T, MITANI T, INUI H, YAMAJI R: Castration influences intestinal microflora and induces abdominal obesity in high-fat diet-fed mice. Sci Rep 6, 2016. https://doi.org/10.1038/srep23001

HARMAN SM, METTER EJ, TOBIN JD, PEARSON J, BLACKMAN MR: Longitudinal effects of aging on serum total and free testosterone levels in healthy men. Baltimore Longitudinal Study of Aging. J Clin Endocrinol Metab 86: 724-731, 2001. https://doi.org/10.1210/jcem.86.2.7219

JAYUSMAN PA, MOHAMED IN, ALIAS E, DOM SM, SHUID AN: Effects of standardized quassinoid-rich Eurycoma longifolia extract in a rat model of osteoporosis due to testosterone deficiency: A densitometric, morphometric and biomechanical study. J Xray Sci Technol 26: 643-656, 2018. https://doi.org/10.3233/XST17366

JAYUSMAN PA, MOHAMED IN, SHUID AN: The effects of chemical castration with degarelix on bone turnover: Densitometric and biomechanics bone properties of male rats. Int J Endocrinol Metab 16: e64038, 2018. https://doi.org/10.5812/ijem.64038

JIAO Q, PRUZNAK AM, HUBER D, VARY TC, LANG CH: Castration differentially alters basal and leucine-stimulated tissue protein synthesis in skeletal muscle and adipose tissue. Am J Physiol Endocrinol Metab 297: E1222-E1232, 2009. https://doi.org/10.1152/ajpendo.00473.2009

KAKOLEWSKI JW, COX VC, VALENSTEIN ES: Sex differences in body-weight change following gonadectomy of rats. Psychol Rep 22: 547-554, 1968. https://doi.org/10.2466/pr0.1968.22.2.547

KAPLAN SA, MEEHAN AG, SHAH A: The age related decrease in testosterone is significantly exacerbated in obese men with the metabolic syndrome. What are the implications for the relatively high incidence of erectile dysfunction observed in these men? J Urol 176: 1524-1528, 2006. https://doi.org/10.1016/j.juro.2006.06.003

KATZNELSON L, FINKELSTEIN JS, SCHOENFELD DA, ROSENTHAL DI, ANDERSON EJ, KLIBANSKI A: Increase in bone density and lean body mass during testosterone administration in men with acquired hypogonadism. J Clin Endocrinol Metab 81: 4358-4365, 1996. https://doi.org/10.1210/jcem.81.12.8954042

LEDIKWE JH, SMICIKLAS-WRIGHT H, MITCHELL DC, JENSEN GL, FRIEDMANN JM, STILL CD: Nutritional risk assessment and obesity in rural older adults: a sex difference. Am J Clin Nutr 77: 551-558, 2003. https://doi.org/10.1093/ajen/77.3.551

LEE SY, GALLAGHER D: Assessment methods in human body composition. Curr Opin Clin Nutr Metab Care 11: 566-572, 2008. https://doi.org/10.1097/MCO.0b013e32830b5f23

LI X, OMINSKY MS, VILLASENOR KS, NIU QT, ASUNCION FJ, XIA X, GRISANTI M, WRONSKI TJ, SIMONET WS, KE HZ: Sclerostin antibody reverses bone loss by increasing bone formation and decreasing bone resorption in a rat model of male osteoporosis. Endocrinology 159: 260-271, 2018. https://doi.org/10.1210/en.2017-00794

LIM S, KIM JH, YOON JW, KANG SM, CHOI SH, PARK YJ, KIM KW, LIM JY, PARK KS, JANG HC: Sarcopenic obesity: prevalence and association with metabolic syndrome in the Korean Longitudinal Study on Health and Aging (KLoSHA). Diabetes Care 33: 1652-1654, 2010. https://doi.org/10.2337/dc10-0107

LOCHMÜLLER EM, JUNG V, WEUSTEN A, WEHR U, WOLF E, ECKSTEIN F, AMLING M, PRIEMEL M: Precision of high-resolution dual energy X-ray absorptiometry measurements of bone mineral status and body composition in small animal models. Eur Cell Mater 1: 43-51, 2001. https://doi.org/10.22203/eCM.v001a05

MALAFAIA AB, NASSIF PA, RIBAS CA, ARIEDE BL, SUE KN, CRUZ MA: Obesity induction with high fat sucrose in rats. Arq Bras Cir Dig 26 (Suppl 1): 17-21, 2013. https://doi.org/10.1590/S0102$\underline{67202013000600005}$

MAMIKUTTY N, THENT ZC, SAPRI SR, SAHRUDDIN NN, MOHD YUSOF MR, HAJI SUHAIMI F: The establishment of metabolic syndrome model by induction of fructose drinking water in male Wistar rats. Biomed Res Int 2014: 263897, 2014. https://doi.org/10.1155/2014/263897 
MEIER C, NGUYEN TV, HANDELSMAN DJ, SCHINDLER C, KUSHNIR MM, ROCKWOOD AL, MEIKLE AW, CENTER JR, EISMAN JA, SEIBEL MJ: Endogenous sex hormones and incident fracture risk in older men: The Dubbo Osteoporosis Epidemiology Study. Arch Intern Med 168: 47-54, 2008. https://doi.org/10.1001/archinternmed.2007.2

MELLSTROM D, JOHNELL O, LJUNGGREN O, ERIKSSON AL, LORENTZON M, MALLMIN H, HOLMBERG A, REDLUND-JOHNELL I, ORWOLL E, OHLSSON C: Free testosterone is an independent predictor of BMD and prevalent fractures in elderly men: MrOS Sweden. J Bone Miner Res 21: 529-535, 2006. https://doi.org/10.1359/jbmr.060110

MORAN JM, MARTIN RR, PEDRERA-CANAL M, ALONSO-TERRON J, RODRIGUEZ-VELASCO FJ, PEDRERA-ZAMORANO JD: Low testosterone levels are associated with poor peripheral bone mineral density and quantitative bone ultrasound at phalanges and calcaneus in healthy elderly men. Biol Res Nurs 17: 169-174, 2015. https://doi.org/10.1177/1099800414532710

MOREAU MF, LIBOUBAN H, LEGRAND E, BASLÉ MF, AUDRAN M, CHAPPARD D: Lean, fat and bone masses are influenced by orchidectomy in the rat. A densitometric X-ray absorptiometric study. J Musculoskelet Neuronal Interact 1: 209-213, 2001.

NOVELLI EL, DINIZ YS, GALHARDI CM, EBAID GM, RODRIGUES HG, MANI F, FERNANDES AA, CICOGNA AC, NOVELLI FILHO JL: Anthropometrical parameters and markers of obesity in rats. Lab Anim 41: 111-119, 2007. https://doi.org/10.1258/002367707779399518

PASQUALI R, CASIMIRRI F, CANTOBELLI S, MELCHIONDA N, MORSELLI LABATE AM, FABBRI R, CAPELLI M, BORTOLUZZI L: Effect of obesity and body fat distribution on sex hormones and insulin in men. Metabolism 40: 101-104, 1991. https://doi.org/10.1016/0026-0495(91)90199-7

POTIKANOND S, RATTANACHOTE P, PINTANA H, SUNTORNSARATOON P, CHAROENPHANDHU N, CHATTIPAKORN N, CHATTIPAKORN S: Obesity does not aggravate osteoporosis or osteoblastic insulin resistance in orchiectomized rats. J Endocrinol 228: 85-95, 2016. https://doi.org/10.1530/JOE-15-0333

RUFF CB: Body mass prediction from skeletal frame size in elite athletes. Am J Phys Anthropol 113: 507-517, 2000. https://doi.org/10.1002/1096-8644(200012)113:4<507::AID-AJPA5>3.0.CO;2-F

SAKI F, KASAEE SR, SADEGHIAN F, TALEZADEH P, RANJBAR OMRANI GH: The effect of testosterone itself and in combination with letrozole on bone mineral density in male rats. J Bone Miner Metab 37: 668-675, 2018. https://doi.org/10.1007/s00774-018-0972-6

SCHROEDER M, SHBIRO L, ZAGOORY-SHARON O, MORAN TH, WELLER A: Toward an animal model of childhood-onset obesity: follow-up of OLETF rats during pregnancy and lactation. Am J Physiol Regul Integr Comp Physiol 296: R224-R232, 2008. https://doi.org/10.1152/ajpregu.90697.2008

STARCEVIC K, FILIPOVIC N, SPERANDA M, DIDARA M, MASEK T: The influence of sex and gonadectomy on hepatic and brain fatty acid composition, lipogenesis and beta-oxidation. J Anim Physiol Anim Nutr (Berl) 101: 649-657, 2017. https://doi.org/10.1111/jpn.12575

SVARTBERG J, VON MUHLEN D, SUNDSFJORD J, JORDE R: Waist circumference and testosterone levels in community dwelling men. The Tromso study. Eur J Epidemiol 19: 657-663, 2004. https://doi.org/10.1023/B:EJEP.0000036809.30558.8f

TAYLOR SR, MEADOWCRAFT LM, WILLIAMSON B: Prevalence, pathophysiology, and management of androgen deficiency in men with metabolic syndrome, type 2 diabetes mellitus, or both. Pharmacotherapy 35: 780-792, 2015. https://doi.org/10.1002/phar.1623

TORREMADE-BARREDA J, RODRIGUEZ-TOLRA J, ROMAN-ROMERA I, PADRO-MIQUEL A, RIUS-MORENO J, FRANCO-MIRANDA E: Testosterone-deficiency as a risk factor for hip fracture in eldery men. Actas Urol Esp 37: 142-146, 2013. https://doi.org/10.1016/j.acuroe.2012.06.005

VANDERSCHUEREN D, VAN HERCK E, SUIKER AM, VISSER WJ, SCHOT LP, BOUILLON R: Bone and mineral metabolism in aged male rats: short and long term effects of androgen deficiency. Endocrinology 130: 2906-2916, 1992. https://doi.org/10.1210/endo.130.5.1572302

VANDERSCHUEREN D, VANDENPUT L, BOONEN S, VAN HERCK E, SWINNEN JV, BOUILLON R: An aged rat model of partial androgen deficiency: Prevention of both loss of bone and lean body mass by low-dose androgen replacement. Endocrinology 141: 1642-1647, 2000. https://doi.org/10.1210/endo.141.5.7472 
VENKEN K, BOONEN S, VAN HERCK E, VANDENPUT L, KUMAR N, SITRUK-WARE R, SUNDARAM K, BOUILLON R, VANDERSCHUEREN D: Bone and muscle protective potential of the prostate-sparing synthetic androgen 7alpha-methyl-19-nortestosterone: evidence from the aged orchidectomized male rat model. Bone 36: 663-670, 2005. https://doi.org/10.1016/j.bone.2005.01.003

VILLAREAL DT, APOVIAN CM, KUSHNER RF, KLEIN S: Obesity in older adults: technical review and position statement of the American Society for Nutrition and NAASO, The Obesity Society. Obes Res 13: 1849-1863, 2005. https://doi.org/10.1038/oby.2005.228

WADE GN, BARTNESS TJ: Effects of photoperiod and gonadectomy on food intake, body weight, and body composition in Siberian hamsters. Am J Physiology 246: R26-R30, 1984. https://doi.org/10.1152/ajpregu.1984.246.1.R26

WANNAMETHEE SG, ATKINS JL: Muscle loss and obesity: the health implications of sarcopenia and sarcopenic obesity. Proc Nutr Soc 74: 405-412, 2015. https://doi.org/10.1017/S002966511500169X

ZÜGEL M, QIU S, LASZLO R, BOSNYÁK E, WEIGT C, MÜLLER D, DIEL P, STEINACKER JM, SCHUMANN $\mathrm{U}$ : The role of sex, adiposity, and gonadectomy in the regulation of irisin secretion. Endocrine 54: 101-110, 2016. https://doi.org/10.1007/s12020-016-0913-x

ZUMOFF B, STRAIN GW, MILLER LK, ROSNER W, SENIE R, SERES DS, ROSENFELD RS: Plasma free and non-sex-hormone-binding-globulin-bound testosterone are decreased in obese men in proportion to their degree of obesity. J Clin Endocrinol Metab 71: 929-931, 1990. https://doi.org/10.1210/jcem-71-4-929 